\title{
RE-POSITIONING THE COMPETENCES OF BEGINNER TEACHERS IN SOUTH AFRICA: A CAPABILITIES PERSPECTIVE
}

\author{
D. E. Esau \\ Senior Phase and FET \\ Cape Peninsula University of Technology Wellington Campus \\ Wellington, South Africa \\ e-mail: esaud@cput.ac.za
}

\section{R. Maarman}

Faculty of Education

University of the Western Cape

Cape Town, South Africa

e-mail: rmaarman@uwc.ac.za

\section{ABSTRACT}

On entering the teaching profession, beginner teachers in South Africa are expected to comply with requirements underlying the National Policy Framework (NPF) for teacher education in South Africa (Department of Education 2006, 11). These requirements are stipulated as follows: "A teacher needs to be a specialist in a particular learning area, subject or phase; a specialist in teaching and learning; a specialist in assessment; a curriculum developer; a leader, administrator and manager; a scholar and lifelong learner; and a professional who plays a community, citizenship, and pastoral role". Recent studies have however revealed that there are many concerns among newly appointed teachers about their readiness to fulfil these roles. This has lead us to do an explorative investigation in an effort to re-position the capabilities of beginner teachers. The qualitative data extrapolated from a literature investigation, teacher education policy and semi-structured interviews will guide us in formulating findings, pertinent to establishing a support strategy in what they deem as the most challenging aspects in and around the classroom. The investigation is underpinned by Sen's (1980) capabilities approach which offers a yet unexplored lens through which to understand the importance of supporting beginner teachers to enhance their problem solving skills, to enable them to made sound decision and to enable them to deal with the challenges in the classroom (Maarman 2009, 321).

Keywords: beginner teachers, capabilities, challenges, mentoring, support, teacher education policy

\section{INTRODUCTION}

Education is the cornerstone of development and change in any society and the role of the teacher as one of the architects in this process is both valuable and highly significant.

In the past decade, the issue of support for beginner teachers has been a topic of interest 
across the world and of late, in South Africa as well (Esau and Maarman 2017, 1). Many changes have taken place in respect of, not only the long overdue acknowledgement and recognition of teacher competence, but issues relating to the development of newly appointed teachers as well.

This article will focus on re-positioning these competences which we have redefined as the "capabilities" of beginner teachers. This is done by focusing on the fulfilment of the objectives of the investigation which are: to identify the aspects of their capability sets that beginner teachers find most challenging; to investigate the nature of current school support programmes to enhance beginner teachers' capability sets; to investigate what constitutes an effective school support programme for the growth and development of beginner teachers.

We furthermore draw on the findings of a qualitative investigation, after interviewing six beginner teachers, to get a better understanding of their perceptions about intervention initiatives with regard to their development to enrich their capabilities in relation to the roles which are expected of them as teachers. We maintain that issues pertaining to the challenges of beginner teachers' preparedness should take centre-stage when considering policy formation and implementation. This we explore by turning our attention to the development of teacher education policy over the years and its effects on South African teachers and their work. The findings of the investigation will be presented and a capability-based mentoring programme of support for beginner teachers will be offered. We start off by introducing the CA as theoretical basis for the investigation, its interrelatedness with teacher education and its potential as an evaluative instrument for this investigation.

\section{THE CAPABILITY APPROACH AS THEORETICAL FOUNDATION}

With its roots firmly in the philosophical world of Aristotle, Classical Political Economic system and Marxism, Sen's capabilities approach links the achievement of quality learning outcomes with regard to the basic competences of beginner teachers to his vision for reaching achieved functionings, which refers to one's ability to be or to do. Sen $(1980,31)$ argues that well-being (living or doing well) can be effectively applied to the capability sets of people. The capabilities approach focuses on the realisation of capabilities such as human development, nourishment and self-respect, but relative in the space of material possessions and financial means required to realize those capabilities. Education should assist a person to develop abilities to think critically and creatively, to solve problems, to make informed decisions, to cope, to manage new situations and to communicate effectively. Focusing on education and development, the capabilities approach suggests the initiation of concerted efforts to enhance personal capabilities, while considering the relationship between education and human 
development. Sen $(1980,47)$ purports that "learning "to do" includes and is related to what is done in order to fulfil their needs. This he says relates to the "manual, or psychomotor, skills for immediate needs and day to day functioning" (Sen, 1980, 47). Within the sphere of teacher education and more specifically, support for beginner teachers, the "capability sets represent those variables embedded within the capabilities approach used to explore and explain the perceptions of beginner teachers about support to enhance their capabilities in relation to teacher education policy" (Sen, 1980, 47) Development and education are thus considered as crucial elements to improve capabilities. A person's capabilities can be described as the successes that a person is able to accomplish while being allowed to make choices as to which capabilities he or she wants to focus on in achieving established goals.

By using Sen's (1980) capabilities approach, this article argues for a theoretical foundation on which to re-position the capabilities of beginner teachers as it lends itself to highlight the well-being of the beginner teacher, taking into account their capabilities in order to reach their full potential. Furthermore, the capabilities approach takes into account "personal and structural factors, or conversion factors, which influence individual agency - the ability to make use of capabilities" (Robeyns 2005, 108). In addition to this, Sen $(1980,214)$ requires of us "to consider equality of capabilities through education". So instead of looking at similar levels of inputs, we can now ask how free beginner teachers are to be involved in the education settings which are not necessarily prescribe to them, but that which they may deem appropriate and beneficial for themselves.

To fulfil the aim of this article we need to look at setting an equal stage for beginner teachers' capabilities by means of a support structure. The link between the capabilities approach and teacher education is therefore meaningful and "mutually enhancing" (Saito 2003, 17). As such the achievement of quality learning outcomes with regard to the NPF for Teacher Education and Development in South Africa (Department of Education 2006, 5) could be successfully linked to Sen's vision for reaching achieved functionings. The capabilities approach is therefore also a useful tool in addressing not only the human resource needs of the beginner teacher, but also their development needs and aspirations as well-rounded individuals.

The capabilities approach further supports the understanding of the education process by providing "capability sets as measures of analysis" (Daniel-Oghenetega and Maarman 2010, 129). Sen's view on education is that of "an overarching capability that should expand other capabilities; whether it be gaining skills and concomitant opportunities, or gaining other intrinsically important capabilities, such as critical thought, respect and empathy" (Unterhalter, Vaughan and Walker 2007, 4). The capabilities approach therefore proposes that the in order for beginner teachers to achieve high quality learning outcomes the requirements of their 
performance should the availability of resources to reach the outcomes. Learning "to be and to live together" underlines the importance of interaction between internal and external factors. The internal factors refer to the theory "that reality for each person is defined by him or herself and is directly linked to the notion of agency" according to the capabilities approach (Sen 1992, 184). Bandura (1977) refers to external factors as "the need for constant social support and collective well-being as a prerequisite to individual well-being, and recognise the impact of external pressure" $(1977,143)$. The capabilities approach is valuable in the investigation of beginner teachers' competences in relation to the NPF of 2006 because their voices and values represent a broader understanding and analysis of well-being. The impact of this and other policy formations pertaining to teacher education and support for beginner teachers will be discussed in the next section.

\section{THE IMPACT OF POLICY DEVELOPMENTS ON THE RE-POSITIONING OF BEGINNER TEACHERS' CAPABILITIES}

The assertion of Maarman $(2009,317)$ and Wolhuter $(2014,6)$ that "both the history of education as a discipline and the historiography of South African education are controversial and that teacher education programmes have been severely marginalised", not only refers to the importance of teacher education across the generations but it also necessitates the fostering of a greater understanding of past events that shaped the current education system, theories and teacher education policies. Teacher education policies navigates through many stages and phases from when they are planned and adopted to when teachers are supposed to put them in practice. Only when we investigate the history and origins of policy change, can we get a better understanding of the extent to which these policies were managed, implemented and monitored over many years.

The National Education Policy Initiative (NEPI 1993), a project carried out by the National Education Co-ordinating Committee (NECC 1993), began a process of policy debate between 1990 and 1993 which saw the first steps in building an inspirational vision of a democratic South African education and training system. NEPI critically examined policy options in all areas of education, based on the ideals of the broad democratic movement. The following recommendations were concluded: an inclusive policy for both urban and rural communities, a focus towards capacity-building on rural black colleges and the closure of poorly functioning colleges - but the latter was rejected on the grounds that this would waste existing resources.

"Decades of social and economic discrimination against black South Africans left a legacy of income inequality along racial lines" (Jansen and Taylor 2003, 1). The status-quo of teacher 
training colleges, which were administered along racial and ethnic lines, required redress through drastic measures and, as a result, one department of education was created. This was followed by the establishment of institutions which necessitated the creation of "50 Further Education and Training Colleges (FETs) out of 150, the incorporation of colleges of education into universities, and the merging of technikons and universities in various combinations" (Booyse et al. 2011, 16). Despite these changes, the significant change in the standard of education did not change overnight as it required supportive elements in the face of the myriad of challenges teachers were facing.

In the mid-twentieth century the Eiselen Commission was appointed to design a deliberate plan, shaped by an official discourse of racial segregation, which recommended that "Bantu children should be taught only by Bantu teachers; the ideal who not only have appropriate qualifications and aptitudes, but should also have qualities of obedience, willingness to help, truthfulness, self-control, and the gift to impart knowledge" (Carrim 2003, 320). The ideal teacher thus had to obey certain religious dogmas and therefore had to be compliant with authority.

From 1948 to 1994, many changes occurred in the political, social, and economic spheres with inevitable shifts in official discourses and teacher identities and capabilities. This would lead to different teaching philosophies, approaches and practices. Educational activities were centered on democracy, inclusivity and reflective practices and teachers expected to familiarise themselves with these new theories and to start implementing newly acquired teaching strategies in their classrooms.

This consequently led to "transformation" emerging as the new catchphrase, followed by a myriad of top-down policy initiatives where "teachers were expected to attend numerous workshops and were subjected to extreme answerability and accountability measures" (Oswald $2012,2)$. The new wave of changes in which their capabilities and competences as teachers were constructed was not easily accepted by those on whom it was imposed. Teachers responded by adopting some policies and rejecting others; they started contesting these by means of open resistance and teaching communities had started reconstructing the curriculum and reinterpreting policy to suit individual experiences and interests.

Limited empirically-based studies on the development of beginner teachers in relation to the policy relating to their basic competence and the interpretations of such policies and practices currently exist in South Africa. Evidently, these policies have had limited effects on the transactions that take place during the initial year(s) of teaching. For many years, worldwide educational change has been an important topic of interest and these changes inevitably impacted on the capabilities and freedoms of teachers. Policy impact and implications are useful 
aspects in the investigation of beginner teachers' perceptions of their competences because their voices and values are essential to and representative of a broader spectrum and analysis of their well-being and capabilities. This can either directly or indirectly have a bearing on teachers' classroom actions and became clear as we embarked on this research journey to re-position the capability sets of beginner teachers through this empirical investigation.

\section{THE EMPIRICAL INVESTIGATION}

A qualitative research design is used, in line with the phenomenology research methodology, which lends itself to developing an understanding of a particular phenomenon. This combination of design and methodology will give full impetus to the investigation. Phenomenology originates from philosopher, Edmund Husserl (1963), and later re-developed by Heidegger (1982). The phenomenological approach was adopted in this article as it allows the investigation to describe the meanings of a lived experience and is useful in trying to understand a particular phenomenon of interest within its lived world.

Permission to undertake the investigation was obtained from the appropriate authorities, which included the Ethics Committee of the University of the Western Cape and the Western Cape Education Department. An abstract containing a declaration of the research design and method for data collection accompanied these applications, and the privacy, confidentiality and anonymity of participants were respected and guaranteed.

The qualitative approach was found to be the most suitable method of inquiry for the investigation with purposeful sampling being applied. Six beginner teachers (being one to three years into the teaching profession) from three high schools in the Western Cape were purposefully identified and selected. The investigation was conducted at three schools in three different education districts in the Western Cape, which are Overberg District, Metro-North District and Metro-East District. The Western Cape Department of Education (WCED) consists of eight education districts, divided into 49 circuits. District offices are primarily responsible for educational management of schools and are respectively servicing four rural districts (West Coast, Cape Winelands, Eden and Karoo, and Overberg) and four urban districts (Metro North, Metro South, Metro East and Metro Central). The decision to choose schools from these three different education districts in the Western Cape was intentional as these three districts are a fair representation of schools in the province. Typically, schools situated in more affluent urban areas normally have a greater advantage in most instances over schools in poorer communities when referring to issues of challenges and support. We were interested to find out how the different context of the schools would influence their perception of the support they receive.

Semi-structured interviews and policy reviews are used to collect data. This fits in 
perfectly with the main objective of the investigation, which is to re-position the capabilities of beginner teacher at the backdrop of teacher education policy within the constructs of the capabilities approach.

A list of the significant aspects (themes) was drawn up in order to describe the meanings in detail. These themes that were identified in the data were representative of important details uncovered during the interviewing process. Transcripts of the recordings were made via a cell phone recorder and backed up on an external drive. This allowed for "completeness of the verbal interaction and provides material for reliability checks" (McMillan and Schumacher 2010, 360). Texts were carefully analysed for clarity and tape recordings were listened to several times to eliminate ambiguity and participants impressions were noted and recorded.

\section{KEY FINDINGS OF THE INVESTIGATION ACCORDING TO THE OBJECTIVES OF THE STUDY}

After a review of the relevant literature and teacher education policy and through analysing the data collected from interviews conducted with the six beginner teachers, the findings of the investigation revealed that for quality teaching and learning to become a reality, it is inevitable that the voices of novice teachers be heard concerning their pains, yearnings, anguish, aspirations, and expectations of growth and development. The following key findings were identified as the most pertinent in the realisation of each of the objectives of the investigation:

Objective 1: To explore beginner teachers' perceptions of their competences in relation to teacher education policy.

- The majority of the respondents noted the practical component of their teacher education to be one of the most important aspects of their training.

- They were in agreement that even though the period of teaching practice was of great value, it did not fully prepare them for the myriad of challenges they are currently facing in the classroom.

- One of the respondents mentioned that the stark reality of suddenly being in charge of a group full of teenagers in the classroom was in direct contrast to the feeling she experienced in their teacher preparation programs where lecturers and peers enveloped them in a safe learning environment.

- Others added by saying that once they started teaching, they quickly realised that their time with other colleagues was reduced to a few hurried minutes at lunch, before, or after school.

- Beginner teachers feel that they are perceived as incompetent to implement the new 
curriculum framework but that their inability to comply is due to inadequate training, administrative overload and an expectation to comply with policy changes.

- Beginner teachers feel that the above sadly dominates their passion for the career.

Objective 2: To identify the aspects of their capability sets that beginner teachers find most challenging.

- Beginner teachers felt they were not adequately prepared for the challenges in the classroom.

- They view the transition from student to teacher as extremely strenuous and difficult and identified lack of support as the biggest contributor to the problem.

- Most of the respondents struggle to manage their classrooms.

- $\quad$ Some mentioned the fact that they are not trained to work with learners with extensive behavioural problems which lead to weak academic performance.

- Violence in and around the classroom, inappropriate sexual behaviours towards teachers were mentioned as some of the frightening realities beginner teachers are confronted with in the classroom on a daily basis.

- Beginner teachers feel that because they were not trained as social workers and most do not even have children of their own yet, they are caught unawares to deal with those kind of challenges at such a young age.

Objective 3: To investigate the nature of current school support programmes to enhance beginner teachers' capability sets.

- The overwhelming majority of respondents have not been through either an induction programme when they started teaching or any form of further support in order to assist them in their development as beginner teachers.

- They feel that they were not introduced to and informed about important issues pertaining to the specific schools' culture, assessment procedures, disciplinary rules and regulations, management structures, and other general administrative requirements. Some of them have not yet met the school's governing body, even after a full year of teaching at the school. Some mentioned that they do attend subject-related workshops arranged by the Western Cape Education Department but that they seldom attend workshops aimed at enhancing their skills and knowledge as teachers.

- Workshops are often outside of the normal school hours when teachers are already overloaded with marking, administrative work as well as extramural activities. 
Objective 4: To investigate what constitutes an effective school support programme for the growth and development of beginner teachers.

- Some of the respondents felt that the kind of support in the form of mentorship that they are offered at their school, should be the norm at every other school in the country, and that, in this way, beginner teachers' will have the opportunity to share their load with the older, more experienced members of staff.

- Other respondents noted that they feel that of a well-structured programme of support would to be implemented at their schools, it would foster a greater level of trust and camaraderie amongst staff and might also lead to greater confidence and improved self-concept in beginner teachers.

- The overall perceptions of beginner teachers about what constitutes an effective school support programme is that they would appreciate it if such a programme can be incorporated in their school day or as unobtrusively as possible as time constraint is a huge factor in a normal school day and they all agree that such an intervention is pivotal if quality teaching and learning is to be promoted.

Based on the above findings of this investigation and as our original contribution to knowledge in the field of teacher education, we have developed a blended capability-based mentoring programme of support for beginner teachers. This programme incorporates modern technology as well as traditional one-on-one mentoring, constructed on the theoretical foundations of goal setting, career development, cognitive mentoring, reflective learning, reverse mentoring and co-operative mentoring.

\section{A CAPABILITY-BASED MENTORING PROGRAMME AS STRATEGY TO REPOSITION BEGINNER TEACHERS' CAPABILITIES}

The nature of mentoring for beginner teachers who participated in the investigation surfaced as an underlying theme from all participants. The authors therefore consolidated the participants' responses in the shape of a mentoring programme based on the capability sets of beginner teachers.

There are many definitions of mentoring but for the purposes of this article we assert that a mentoring programme in essence involves a partnership (short term or long term, depending on the need) where an employee ("mentee") is assigned to someone more experienced ("mentor") whose role it is to provide career guidance to the mentee and to pass on valuable 
aspects of his or her own accumulated experience and wisdom for the benefit of the mentee's personal and professional development (Esau \& Maarman 2017).

When new teachers are appointed, they are given a full work load and are expected to start teaching immediately, often without the benefit of any period of any induction. Newly appointed teachers essentially have to learn how to teach while teaching. A mentoring programme can add real value and provide tangible benefits to many areas of a teacher's performance, such as induction, content knowledge transfer, classroom management, policy implementation, career development, and leadership training. Having opportunities to offer deep, practical knowledge relating to pedagogy, content and experience can be a very rewarding and valuable aspect of effective mentoring (Moir et al. 2009, 39). Mentoring can guide novice teachers to adapt into the profession with more ease, and can assist them in developing and consolidating acquired skills. This will enable them to use more effective, learner-centred approaches in the classroom. Justifications for a mentoring programme cover issues such as effective ways to successfully orientate newly qualified teachers into their new school environment and also can also impact on the quality of teaching and learning in the first few years of teaching (Lasley 1996).

Mentoring relationships should be based on trust, acknowledgment of mutual benefit and a balanced responsibility for conduct, with attention to the confidential nature of the relationship. The process should include the fresh energies that new teachers bring to the system without marginalising the perspectives and wisdom of teachers whose knowledge and experience have deep roots in the past (National Foundation for the Improvement of Education (NFIE) 1999). Induction and the continuous development of teachers must be a continuation and extension of the efforts of initial teacher education, guided by policy and aligned by good practice, and should ultimately result in teachers becoming reflective practitioners. A good mentoring programme is also required to document the new teacher's mentoring experience and journey to discovery. It should therefore encompass an entire system of training, development, and improvement, even beyond the school context.

\section{THE DEVELOPMENT OF A CAPABILITY-BASED MENTORING PROGRAMME}

"For more than a decade, clear and consistent research has shown that the quality of teachers is the most powerful school-related determinant of student success" (Moir et al. 2009, 205). In the light of this revelation and in answer to the outcry of beginner teachers for school support to enhance their capability sets, we have developed of a mentoring programme (see Figure 1) after analysing the data and formulating the research findings.

There is a definite and deliberate divergence from the traditional in-person mentoring 
programme as the sole method of mentoring towards a more modern approach of using a combination of one-on-one mentoring in conjunction with modern technology. This is believed to resonate more appropriately with the younger generation teachers. Training will be provided to both mentors and mentees as an introduction to the mentoring process.
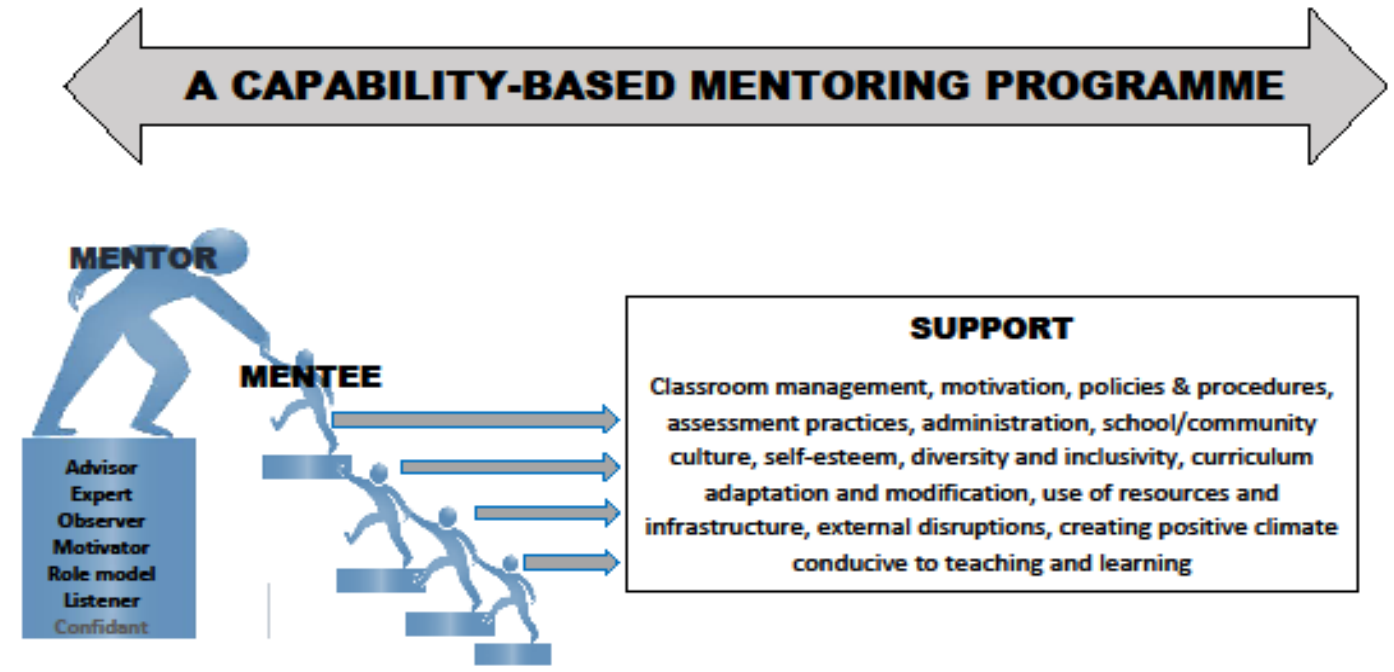

SUPPORT
Classroom management, motivation, policies \& procedures,
assessment practices, administration, school/community
culture, self-esteem, diversity and inclusivity, curriculum
adaptation and modification, use of resources and
infrastructure, external disruptions, creating positive climate
conducive to teaching and learning

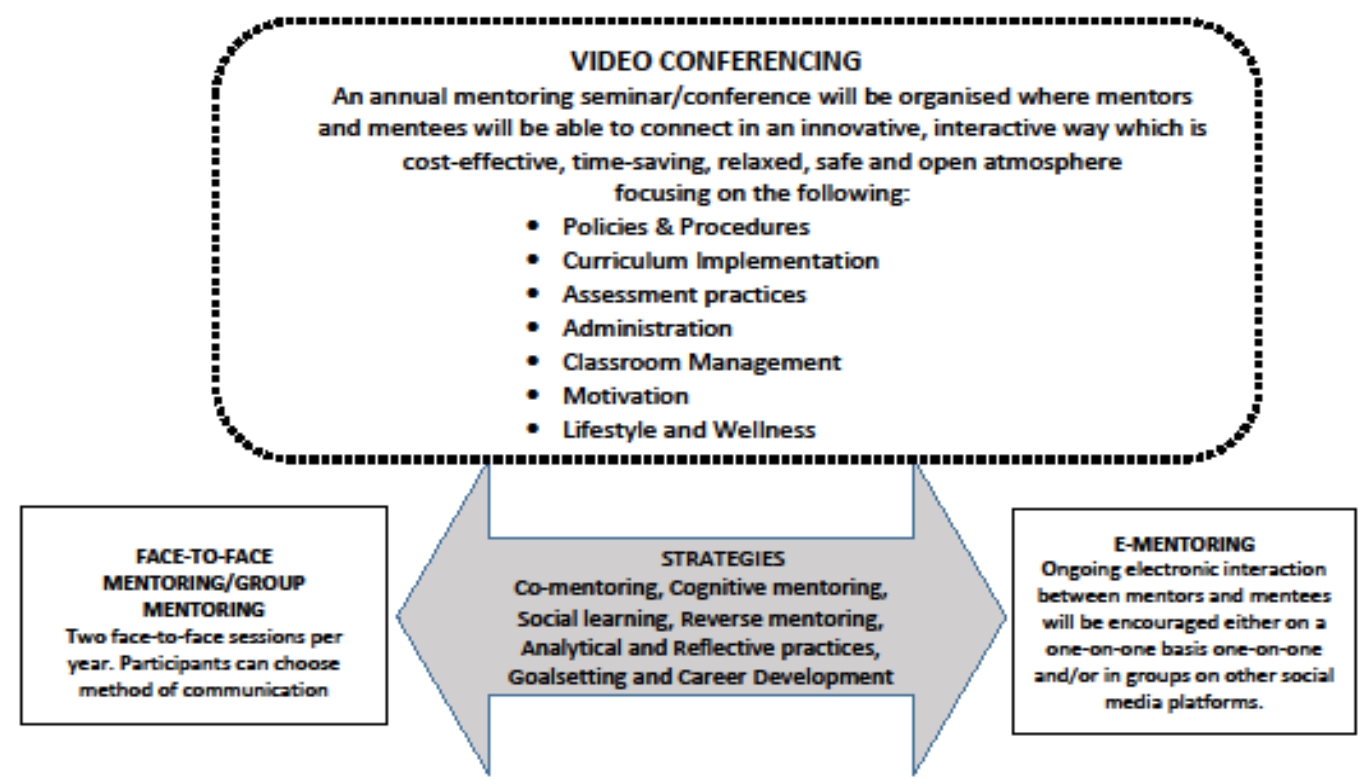

TIMELINE (3-YEAR CYCLE)

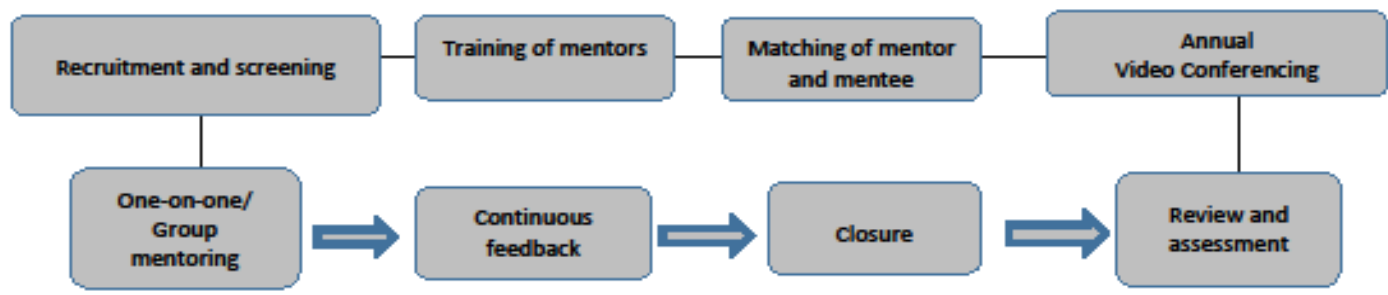

Figure 1: A capability-based mentoring programme (Source: "Exploring beginner teachers' perceptions of school support to enhance their capability sets in relation to teacher education policy" Esau \& Maarman 2017, 191). 
Our mentoring initiative will be integrated with and should be seen as an extension to existing policies and programmes in order to transform support programmes in their current form of existence. It is hoped that the implementation of this programme will not just be viewed as a "nice-to-have", another new "HR initiative" or seen as "yet another workshop", but rather as an instrument of school re-culturing and an effective change agent in teacher education in South African high schools.

The mentoring programme, being our contribution to the field of teacher education, is built on the following theoretical foundations, which will become evident and will become clear as the various elements of the programme are unfolded: developmental goal setting and career development; reverse mentoring; cognitive mentoring; and analytical and reflective practices.

\section{ROLE PLAYERS AND ELEMENTS OF THE MENTORING PROGRAMME}

The following role players will be recruited as integral functions of the programme:

A project coordinator will perform the managing, leading and coordination roles of the mentoring programme. This should be a person fully committed to the realisation of the programme and one who fully understands the project to guarantee the success thereof.

Mentors: Volunteers and others will be identified, recruited and invited based on their experience, skill sets, knowledge, expertise, professional attributes, development level and backgrounds, and should be able to identify the academic, professional, and social needs of new teachers. Initially a group of five mentors will be appointed to serve the eight education districts in the Western Cape. They will form a pool experts that mentees can tap into whenever they need guidance and assistance on various matters relating to, but not limited to, the following: facilitating reflective practice classroom management; motivation; policies and procedures; assessment practices; administration; school/community culture; self-esteem; diversity and inclusivity; curriculum adaptation and modification; establishing collaborations based on trust; comradery and confidentiality; use of technology and other resources; ensuring that the professional development of new teachers are prioritised; creating a positive climate conducive to teaching and learning; and strategies to deal with external disruptions. An encouraging contribution to the mentoring programme will be if mentors volunteer for the programme as this would be a clear sign of their level of commitment and involvement. Screening and recruitment therefore becomes an important element of the programme. Mentors will be carefully screened to determine their commitment to fulfilling the goals and purpose of the programme, their availability, and compatibility with personality types.

Mentees: As established from the interview data collected during the empirical 
investigation novice teachers felt that they could derive numerous benefits from a successful workplace mentoring programme. Even though the ideal situation would be for all beginner teachers to participate in this programme that has been created specifically around their developmental needs, there is no intention to enforce the programme on any person. It is believed that voluntary participation can lead to greater levels of commitment. Invitations to participate in the mentoring programme will therefore be sent to beginner teachers in schools across the Western Cape.

The mentoring programme is built on the foundation that induction and initial support will be done as a matter of urgency within the school to efficiently impact the quality of training and development in its entirety, and the improvement of the country as a whole. For any mentoring programme to be successfully implemented, the whole school community needs to be in agreement with the implementation of a mentoring programme, and they need to relate to it as an essential tool and experience that can make a meaningful difference to the broader school community.

The training of mentees will take place during induction and the mentoring process. Mentees will be briefed on the following aspects: goal and setting and expectations of the mentoring process; establishing good rapport with the mentors; respecting mentors' boundaries and time; developing reflective cognitive skills; openness to share weaknesses and strengths; dealing with constructive feedback; and embracing the use of technology as mentoring tool.

The recruitment and selection process of mentors will initially deliver a pool of approximately ten seasoned current and former teachers - specialists in their fields - and will increase as and when the need arises. Although this is a school-initiated support programme, mentors will not necessarily be physically based at schools as activities will all occur online. All mentors will participate at different times and phases of the programme, initially as part of the video conferencing session and later through continuous guidance and support sessions as and when required by mentees. Each mentor will focus on his or her own area of expertise. It is therefore important that mentees build a good rapport with all mentors and vice versa.

As this mentoring programme lends itself to a combination of online, one-on-one, and group interactions, the matching process will require all mentors and mentees to build good mutual rapport as throughout the process mentees will have the freedom to identify and approach whoever they need at a specific time within the parameters of the mentorship agreement.

Opportunities will be created for mentors and mentees to establish a mentorship agreement, during which developmental goals and objectives will be determined as well as expectations, methodologies, confidentiality, logistical issues, evaluation criteria, feedback and 
closure of the programme. All of the aforementioned will be documented into a learning contract which will serve as a memorandum of agreement and understanding, and at the same time as a useful tool reminding participants about important aspects of the mentoring relationship. Figure 1 presents the structure, theory and role clarifications of the mentoring programme.

\section{IMPLEMENTATION OF THE PROGRAMME IN RESPONSE TO THE FINDINGS}

\section{Video conferencing/Webinar}

From the data gathered during the empirical investigation, it is clear that beginner teachers need support and intervention that do not add to their already hectic school programmes and administrative workload. For this reason and for the reasons of being relevant to the needs of the modern teacher, most of the interaction of this programme would take place via modern technology. The decision to incorporate video conferencing in this mentoring programme is grounded on the fact that it is time-saving and cost-effective, and novice teachers can relate to this method of mentoring more readily. Beginner teachers have expressed the fact that they often need to attend workshops and seminars after school hours, which often leads to exhaustion and apathy towards training and development efforts. (Norman 2016, 22) describes the use of integration of technology in education as ethical practices that facilitate more efficient learning, boosting capacity, productivity and performance, which can be used to inspire positive change in education. However, it is essential that the participants in the mentoring process should realise their respective responsibilities to keep abreast of the latest developments in technology used for the purpose of online mentoring and that the success of the process depend on their interactions.

- The initial mentoring phase via video conferencing will be planned in close collaboration with the Western Cape Education Department as these one-day sessions will take place on an agreed date for each of the eight education districts.

- $\quad$ Each of the appointed mentors will have appointed time slots during which to present their topic of interest, which will address the pressing issues and challenges of beginner teachers such as goal setting, classroom management, assessment practices, the importance of wellness and health, curriculum implementation, education policies in practice, evaluation and appraisal programmes, and motivational sessions.

- Because of the interactive nature of video-conferencing, time will be allowed for question and answer sessions, discussions and interactive group activities. 
- Efforts will be made to incorporate WCED staff to facilitate the on-site activities as far as possible and to upload the content on WCED's online portal (Western Cape Education Department e-Portal), (see Figure 2), which is a growing resource for learners, teachers, principals, parents and governing body members alike.

- The e-Portal (www.wcedeportal.co.za) enables the uploading and downloading of educational videos and advice on difficult topics, and it provides opportunities for parents to be actively involved in their children's education.
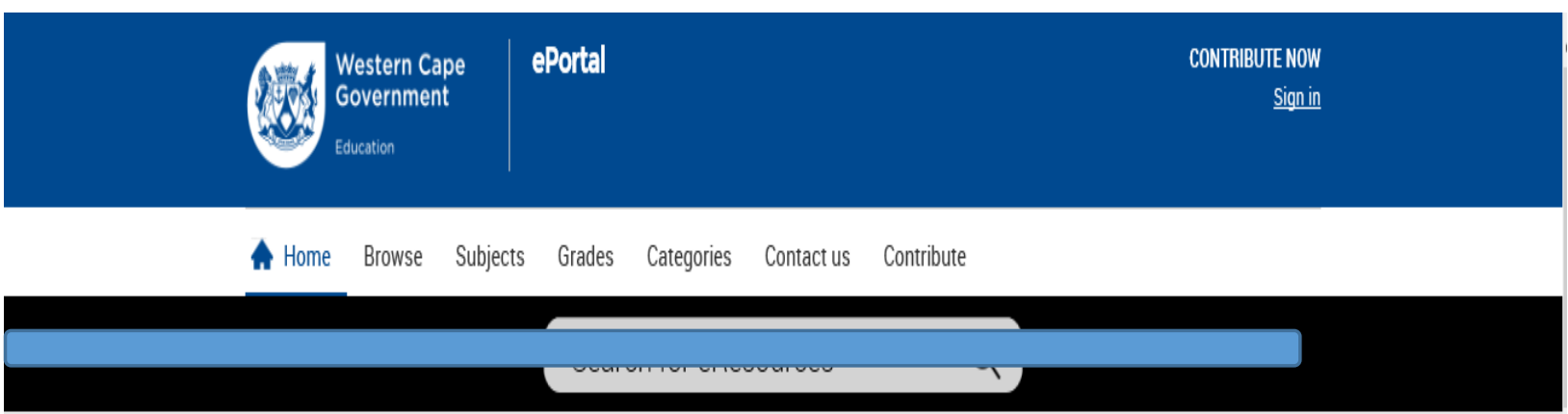

\section{Welcome to the Western Cape Education Department ePortal}

Explore educational apps, videos, ebooks and courses

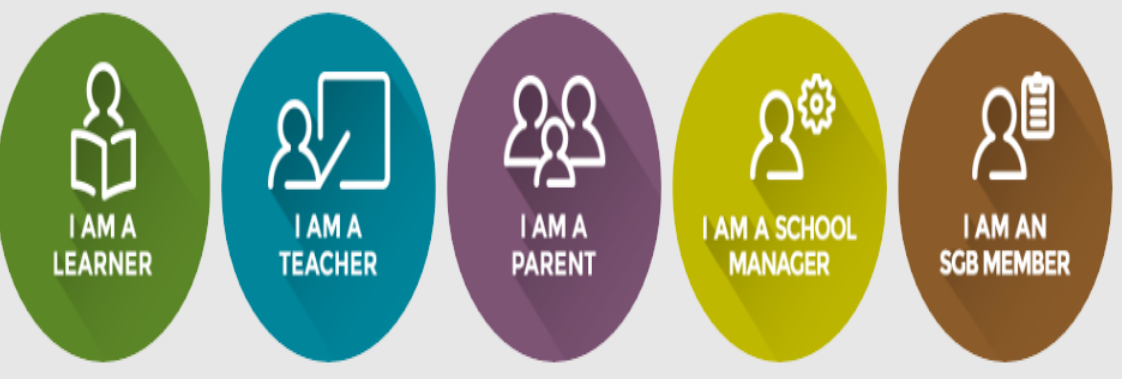

Figure 2: Western Cape Education Department e-Portal (WCED 2016)

(Source: http://wcedeportal.co.za/ Western Cape Government: Education e-Portal)

\section{One-on-one, reverse mentoring}

- One-on-one mentoring will happen as per agreement between both participants.

- This type of interaction serves as "an effective relationship that is based on mutual respect and will be a risk-free zone for the mentee to examine options and brainstorm strategies" (Bey and Holmes 1992, 17). It is said that we "talk our way to understanding when we are given freedom and encouragement to express our creative thoughts without fear of 
judgement" (Freedman and Jaffe 1993, 23). Such a relationship lends itself to attentive listening, re-negotiation, reflective learning and reverse mentoring.

- Mentors and mentees should agree on a suitable format, meeting times and venues which are mutually convenient and conducive to focused and confidential discussions.

- The meeting space should be held in a non-threatening space to ensure the safety, security and confidentiality of the mentoring relationship.

- One element of one-on-one mentoring that can be included in the meeting time is observations.

- There are certain situations that cannot be recreated virtually and therefore should rather be experienced first-hand. Mentees might therefore feel that they need immediate guidance or input from the mentor, for example, while teaching a specific subject or dealing with a specific aspect of classroom management or discipline issues.

\section{e-Mentoring}

- In line with the latest technology and in accordance with the latest communication trends, the component of e-mentoring in this programme will find great relevance with the beginner teacher and their development needs.

- The programme provides for the mentee to exercise the option of who of the mentors to consult depending what guidance, information or support is needed at a specific time.

- A "cohort" or pool of mentors will be available online at any agreed time to provide mentees with the necessary support and guidance. This will at first be initiated through existing channels of online connectivity, such as e-mails, instant text messaging and other secure social media and discussion forums.

- An added feature to these mentors will provide audio and visual recordings in the form of instructional audio and video clips, blogs, vlogs (video blogs) and podcasts.

- As soon the mentoring programme is approved and endorsed by all stakeholders, a request will be lodged with WCED to incorporate the e-mentoring into their e-Portal webpage (see Figure 2).

\section{Reflective and constructive feedback:}

- It is during this phase that cognitive mentoring will be encouraged. This is the process during which mentees honestly reflect on their strengths and weaknesses and communicate that to their mentors.

- The programme of cognitive coaching was developed by Costa and Garmston (2002) and 
defined as "a set way of thinking and a way of working that invites self and others to shape and reshape their thinking and problem-solving capacities" $(2002,22)$.

- Mentors thus act as intermediary between the mentees and their thoughts about their own skills and abilities. Based on what transpires from this process, further guidance and support will be discussed.

\section{Closure}

- A successful learning contract is only completed when there is evidence that all learning outcomes have been achieved and that mentees are able to apply the knowledge and skills acquired.

- At this stage the participants in the process should prepare to assess the effectiveness of the programme which will be determined ultimately by evidence of positive outcomes for the mentee.

- $\quad$ Consequently, the mentoring relationship will be brought to an end.

A manual checklist system will be used as a mechanism to monitor contact time and online interactions between mentors and mentees. This will be useful in the evaluation of the progress and success rate of the programme and will assist in future improvement efforts. It will also provide the project coordinator with an overview of the various learning and mentoring styles of participants (see Figure 1 for timelines).

The long-term successes of the programme will be evident when fewer young teachers want to leave the teaching profession, and there is a marked difference in the achievement of performance review indicators and positive feedback from principals, heads of departments and peers concerned with the career development of beginner teachers involved in the programme.

\section{THE CAPABILITY APPROACH AS THEORETICAL BASIS FOR THE PROGRAMME}

The rationale behind utilising this approach as a theoretical foundation is two-fold. It is firstly envisaged that the mentoring programme should change and impact the capability set of the novice teacher positively. Capability sets are also seen as valued functionings (i.e. the required competences according to teacher education policy). Secondly, the beginner teacher should feel individually free enough to choose his or her path. This implies that the process of mentoring should assist them in attaining a feeling of accomplishment and competence as a teacher, regardless of whether they choose the valued functioning or not. This theoretical framework 
"takes into account the individual's perspective on what doings and beings (functionings) they regard as valuable" (Sen 1992, 43). All forms of mentoring and support provided for beginner teachers will thus be regarded as what Sen terms "commodities", which refers to various goods and services. In the instance of the capability-based mentoring programme this will focus on curricular and non-curricular competencies. Based on Sen's (1992) emphasis on the "use or application of these commodities" by the mentees, it is important to note that how these commodities will be used, depends on "individual and non-individual features, called conversion factors - someone's skills and knowledge, traits of character, social norms and legal framework of not only societal factors, but also current financial situation and other resources available to them" (Sen 1992, 70-71).

While designing this programme we considered that we carefully attend to develop critical teaching skills and equalise the chances between individuals by, for instance, equipping them to manage an ill-disciplined group of learners; guiding them to device their own professional growth plan and work hard towards achieving them; and assisting the novice teacher to develop reflective practices and the ability to work together with various stakeholders in a multidisciplinary and diverse education setting.

Another appealing factor that attracts us to use Sen's approach to support this mentoring programme is that the capabilities approach proposes that we adapt certain preferences, thereby asserting that people will aspire to achieving their goals which they view as achievable. The opposite can also be true that people would not believe that they can achieve greatness because of limitations such as norms, socio-economic and political considerations, stereotypes, discrimination and other subtle forms of discrimination in the workplace. This phenomenon of self-limitation" is usually not a matter of informed choices of individuals, but it is based on previous experiences and involves excluding options that are often unthinkable" (Bourdieu 1979, 130). This was clearly evident in the findings of the investigation as it revealed that the competences as outlined in teacher education policy limit novice teachers' freedoms by being too prescriptive and specific. They make beginner teachers feel that - given the huge administrative load, overcrowded classrooms, pressure to complete the curriculum in due time, etc. - that they will never be as competent and confident in their work as their older, more experienced counterparts as well as their peers in more affluent and well-resourced schools. This makes this mentoring programme relevant and necessary due to a clear focus on preparing novice teachers to become the best teachers they can become. Because the programme is built on the premise of individual needs, choices and freedoms, novice teachers will be encouraged to be actively involved, motivated and self-reflective in all phases of the programme.

Another advantage of using the capabilities approach to evaluate the mentoring 
programme is that it correlates with the notion that commodities in themselves, such as workshops and training sessions, are not enough to equip the beginner teacher with all the tools to comply with the criteria of a "good" teacher, in other words is not concerned with a simple transfer of knowledge. What will rather be of vital importance is the establishment of good rapport between mentors and mentees. These relationships should be based on trust and knowledge of the life and world of the teacher as well as an awareness of their individual professional needs. It can therefore be understood and concluded that when we concentrate on measuring selected outcomes along with the enhancement of capability sets of beginner teachers we begin to broaden the concept of access to opportunities in teacher education and development.

\section{EVALUATING THE PROGRAMME USING THE CA}

Amartya Sen's capabilities approach is appropriate because real (or substantive) freedom of choice, one of the elements of the mentoring programme, is at the core of his approach. Teacher education is mostly interested in the way teachers are shaped by the school community, how it produces and reproduces quality teachers amidst social and other inequalities. The agency of teachers is not taken seriously into consideration. The evaluation of the programme is also built around Sen's notion that freedom has an intrinsic value - we should value freedom for itself as an imperative component in the successful development of the beginner teacher and that this freedom becomes instrumental in and is a crucial component of them becoming the actors in their own career trajectory (Sen 1985).

\section{CONCLUSION}

Despite reports of South Africa spending over 20 percent of its budget on education, or 6.4 per cent of the gross domestic product (GDP) - which is considerably more than many other emerging market economies - it still performs dismally in international comparisons. South Africa's education system was ranked 138th out of 140 countries in the world (World Economic Forum, 2015-2016). In reference to this, Prew $(2010,1)$ refers to the South African education system as a "high-cost, low-performance system that does not compare favourably with education systems in other African countries, or in similar developing economies". It is for this reason that interventions such as the repositioning of beginner teachers' capabilities take centre stage.

The repositioning of the cability sets of beginner teachers can thus be concluded by highlighting the following main themes which the investigation yielded.

South Africa's education sector is constantly changing to cater in the needs of a 
progressively diverse and often complex society, and there can be no doubt that teachers are one of the most valuable resources in education to facilitate this much-needed change. It is therefore essential that beginner teachers get the best support and guidance to increase performance levels from the very first day they set foot in the classroom.

Evidence exists to suggest that mentoring programmes for beginner teachers deliver sustainable improvements and enhance career development. We have, as our ultimate objective to provide a well-designed mentoring programme based on strong research principles to effectively support novice teachers. It is hoped that this mentoring programme will play a critical role to enhance the induction and development of novice teachers.

The programme was designed in such a way as to be an effective mechanism to advance teaching in South Africa and provide beginner teachers with the necessary tools to achieve success in the process of turning schools into dynamic learning communities, who are capable of facilitating the success of all teachers and students. The mentoring of beginner teachers furthermore provides the tools and resources needed to guide beginner teachers to develop concrete goals and action plans and use reflection as a self-assessment tool.

While it does not create an expectation that these teachers will magically transform the teaching profession, it is hoped that they will use the acquired skills and knowledge gained throughout the programme to impact their sphere of influence and to foster the same critical thinking and exploration skills within their learners.

Beginner teachers will, furthermore, play a key role in encouraging and promoting a mentoring culture in their own and other schools. By equipping them with tools and resources for effective mentoring, there is a good likelihood that the entire school community will equally be transformed, supported and guided to make appropriate decisions concerning their own growth and development.

In addition to implementing our mentoring programme in schools, we will make regular contributions to the Western Cape Education Department's most recently developed e-Portal (WCED 2016) using the elements of this mentoring programme. We also recommend the development of a dedicated, interactive mobile application in order to reach a wider audience of the WCED's intended niche market. Such an application will make sharing and acquiring of information more seamless, affordable and much more accessible.

A further recommendation based on the findings of the investigation, is that an explorative investigation be undertaken to investigate the collaboration among all stakeholders to ensure the smooth transition of beginner teachers into their first few years of teaching. 


\section{REFERENCES}

Bandura, A. 1977. Social Learning Theory. Englewood cliffs, New Jersey: Prentice-Hall.

Bey, T. M. and C. T. Holmes. 1992. Mentoring: Contemporary principles and issues. Association of Teacher Educators, Reston, Va.

Bourdieu, P. 1979. Distinction. Paris: Les Editions de Minuit.

Booyse, J. J., C. S. le Roux, J. Seroto and C. C Wolhuter. (Eds.). 2011. A history of schooling in South Africa: Method and context. Pretoria: Van Schaik.

Carrim, N. 2003. "Teacher identity: Tension between roles." In changing patterns of teacher education in South Africa, policy, practice and prospects, ed. K. Lewin, M. Samuel and Y. Sayed, 306-322, Cape Town: Heinemann.

Costa, A. L. and R. J. Garmston. 2002. Cognitive coaching: A foundation for renaissance schools. Christopher-Gordon Publishers, Inc., 1502 Providence Highway, Suite 12, Norwood, MA.

Daniel-Oghenetega, B. O. and R. F. A. Maarman. 2010. Exploring capabilities of learners in a quintile 1 school in Metro Central of Cape Town. Master's dissertation. Bellville: University of the Western Cape.

Department of Education 2006. "The National Policy Framework. More teachers; Better teachers.” Pretoria.

Esau, D. E. and R. F. A. Maarman. 2017. Exploring beginner teachers' perceptions of school support to enhance their capability sets in relation to teacher education policy. Doctor in Education. Bellville: University of the Western Cape.

Freedman, M. and N. Jaffe, N. 1993. Elder mentors: Giving schools a hand. NASSP Bulletin 77(549): $22-28$.

Heidegger, M. 1982. "The basic problems of phenomenology". Trans. by Albert Hofstadter. Bloomington: Indiana University Press. From the German original of 1975. The text of a lecture course in 1927.

Husserl, E. 1963. Ideas: A general introduction to pure phenomenology. Trans. W. R. Boyce Gibson. New York: Collier Books. From the German original of 1913, originally titled Ideas pertaining to a pure phenomenology and to a phenomenological philosophy, First Book. Newly translated with the full title by Fred Kersten. Dordrecht and Boston: Kluwer Academic Publishers, 1983. Known as Ideas I.

Jansen, J. and N. Taylor. 2003. Educational change in South Africa 1994-2003: Case studies in large scale education reform. Washington DC: World Bank.

Lasley, T. J. 1996. Mentors: They simply believe. Peabody-Journal of Education 7(1): 64-70.

Maarman, R. F. A. 2009. Manifestations of "capabilities poverty" with learners attending informal settlement schools. South African Journal of Education 29(3): 317-331.

McMillan, J. H. and A. Schumacher. 2010. Research in education evidence-based inquiry. $7^{\text {th }}$ Edition. New York: Pearson.

Moir, E., D. Barlin, J. Gless and J. Miles. 2009. New teacher mentoring: Hopes and promise for improving teacher effectiveness. Harvard Education Press. 8 Story Street First Floor, Cambridge, MA 02138.

National Education Co-ordinating Committee. 1993. Education, Oxford University Press/NECC, Cape Town.

National Education Policy Investigation. 1993. Post-secondary Education. Oxford/NECC, Cape Town.

National Foundation for the Improvement of Education. 1999. http://www.nfie.org. 1201 Sixteenth Street, N.W., Washington, DC 20036-3207. Tel: 202-822-7840.

NECC see National Education Co-ordinating Committee.

NEPI see National Education Policy Investigation. 
NFIE see National Foundation for the Improvement of Education.

Norman, S. 2016. Seven benefits of technology integration in the education sphere. Education Technology. http://e-learningindustry.com

Oswald, M. 2012. Including the gifted learner: Perceptions of South African teachers and principals. South African Journal of Education. DOI: 10.15700/saje.v33n1a603

Prew, M. 2010. Millennium development goal \#2 for education: Solution or problem? Centre for Education Policy Development. Mail \& Guardian. http://www.cepd.org.za

Robeyns, I. 2005. The capability approach: A theoretical survey. Journal of Human Development 6(1): 93-114.

Saito, M. 2003. Amartya Sen's capability approach to education: A critical exploration. J Philos Educ 37(1): 17-33.

Sen, A. K. 1980. Equality of what? In Tanner lectures on human values, ed. S. McMurrin. Cambridge: Cambridge University Press.

Sen, A. K. 1985. Commodities and capabilities. Oxford: Elsevier Science.

Sen, A. K. 1992. Inequality re-examined. Oxford: Clarendon Press.

Unterhalter, E., R. Vaughan and M. Walker, 2007. The capability approach and education. Prospero, Human Development and Capability Association (HDCA).

WCED see Western Cape Education Department.

Western Cape Education Department 2016. WCED E-portal. http://www.wcedeportal.co.za

Wolhuter, C. 2014. Weaknesses of South African education in the mirror image of international educational development. South African Journal of Education 34(2) 1 Art. \# 868, 25 pages. http://www.sajournalofeducation.co.za 